\title{
Strategi Pengembangan Banjar Samu, Singapadu Kaler Sebagai Desa Wisata Di Kecamatan Sukawati, Kabupaten Gianyar
}

I Made Suarditya a,1, I Nyoman Sunarta ${ }^{a, 2}$

${ }^{1}$ suarditya@gmail.com, 20airns54@yahoo.com

a Program Studi S1 Destinasi Pariwisata, Fakultas Pariwisata,Universitas Udayana, Jl. Dr. R. Goris, Denpasar, Bali 80232 Indonesia

\section{Abstract}

The research aim is to determine development strategy of Banjar Samu as a tourism village. This research used qualitative and quantitative data with source from primary and secondary data. Observation, interview and documentation are data collection techniques. The sample method used purposive sampling while data analysis used descriptive qualitative and SWOT analysis.

Based on the results, the research indicate is that Banjar Samu have tourism potential which is consisted of natural potentials include panorama of rice fields and water springs. While the potential of culture include: community activities, hospitality and attitude of mutual cooperation, temples: building architecture and religious activity, sacred art of barong landung and another arts entertainment such as joged bumbung, arja, gambelan geguntangan, as well as local craft communities such as wood carving, silver handicrafts, yoga-meditation activity and sekaa such as sekaa gong, joged, geguntangan, arja, angklung, subak and sekaa santi.

Based on the analysis of SWOT Matrix, the results obtained by SO strategies are improving the quality of tourism potential and establish tourist activity. ST strategy is improving the security services. WO strategies are increasing cooperation with the government college, arranging some promotion. WT strategies are providing education and establish a tourist village management system immediately.

Keywords: Tourism Potential, Strategy Development, Tourism Village

\section{PENDAHULUAN}

Bali dan pariwisata merupakan sebuah kata yang sudah tidak asing lagi, bahkan menjadikan kata ini melekat satu sama lain. Meski mempunyai ukuran relatif lebih kecil dengan luas sebesar $5.632,86 \mathrm{~km}^{2}$ atau setara dengan $0,29 \%$ total keseluruhan wilayah Indonesia, Bali telah menjadi salah satu primadona daerah tujuan wisata dunia.

Dalam beberapa tahun terakhir, Bali telah meraih berbagai penghargaan salah satunya pada 8 pebruari 2010 yang mana dinobatkan sebagai The Best Island Destination Asia-Pacific in Asia Pacific pada The Fifth Annual Destin Asian Readers' Choice Awards, penghargaan ini adalah penghargaan ke-3 untuk kategori yang sama di tahun 2007, 2009 serta 2010. Sebelumnya di tahun 2006 dan 2008 Bali juga terpilih sebagai Best Leisure Destin Asian.

Pada situs Travel + Leisure yang berada di New York menobatkan Pulau Bali sebagai pulau terbaik kedua di dunia setelah Pulau Galapagos, Equador. Sedangkan pada peringkat Asia menempati posisi pertama sebagai pulau terbaik setelah mengalahkan Maldives dan Phuket, Thailand. Fakta ini membuktikan bahwa Bali tetap digemari oleh para wisatawan domestik dan mancanegara.
Namun, dengan kebijakan pemerintah yang lebih mengutamakan jumlah kunjungan wisatawan mengakibatkan terancamnya kelestarian lingkungan Bali. Berawal dari kondisi keprihatinan tersebut pariwisata alternatif dirasa mampu menjadi satu solusi untuk mengurangi dampak yang timbul oleh pariwisata massal.

Salah satu bentuk pariwisata alternatif ialah desa wisata. Desa wisata ialah pengembangan suatu wilayah yang berlokasi di suatu desa yang menawarkan keseluruhan suasana pedesaan dengan memanfaatkan segala sumber daya setempat baik berupa alam maupun budaya yang dapat dikembangkan menjadi daya tarik wisata sehingga menarik untuk dikunjungi.

Banjar Samu adalah satu dari lima banjar yang ada di Desa Singapadu Kaler, Kecamatan Sukawati, Kabupaten Gianyar. Pada tanggal 27 September 2015, Bupati Gianyar Anak Agung Gde Agung Baratha Secara resmi telah menetapkan Banjar Samu sebagai desa wisata. Penetapan ini berdasarkan atas daya dukung potensi wisata yang dibisa dimanfaatkan menjadi daya tarik wisata.

Beraneka ragam potensi yang terdapat di Banjar Samu tentu mempunyai peluang untuk dikembangkan. Tetapi, hingga saat ini pemanfaatan dan pengelolaan potensi tersebut 
belum dapat dilakukan secara optimal. Oleh sebab itu, dibutuhkan strategi dalam memberi solusi yang tepat terhadap pengembangan Banjar Samu sebagai desa wisata. Berkaitan dengan hal tersebut, adapun rumusan masalah yang diambil yaitu apa potensi yang dimiliki Banjar Samu sebagai desa wisata dan bagaimana strategi pengembangan Banjar Samu sebagai desa wisata. Sesuai dengan permasalahan tersebut, maka penelitian ini tujuan untuk mengetahui potensi yang dimiliki Banjar Samu sebagai desa wisata dan untuk mengetahui strategi pengembangan Banjar Samu sebagai desa wisata.

\section{TINJAUAN PUSTAKA}

Beberapa kajian penelitian sebelumnya yang dijadikan pembanding adalah penelitian yang dilakukan oleh Sudana (2013) dengan judul "Strategi Pengembangan Desa Wisata Ekologis di Desa Belimbing, Kecamatan Pupuan, Kabupaten Tabanan". Penelitian ini memiliki kesamaan fokus yakni sama-sama mengkaji tentang strategi pengembangan desa wisata, namun lokus dari penelitiannya berbeda.

Selanjutnya penelitian yang berjudul "Pura Puseh, Pura Desa Batuan Dalam Perkembangan Kepariwisataan Bali di Desa Batuan, Kecamatan Sukawati, Kabupaten Gianyar (Kajian Pariwisata Budaya)" yang dilakukan oleh Surina dan Wartha (2014) memiliki kesamaan lokus penelitian yakni samasama berlokasi di Kecamatan Sukawati, Kabupaten Gianyar. Perbedaan penelitian sebelumnya terletak pada fokus penelitiannya, sehingga penelitian ini masih memiliki kesempatan dan penting untuk dilakukan.

Adapun beberapa konsep yang digunakan dalam penelitian ini diantaranya: (1) konsep potensi wisata dari Pendit (1999) yang menjelaskan secara umum potensi wisata dapat dibagi menjadi dua yaitu terdiri dari potensi alam dan potensi budaya". (2) Konsep strategi dari Chandler (dalam Rangkuti, 2015). (3) Konsep pengembangan dari Yoeti (2008). (4) Konsep desa wisata menurut Putra (dalam Sudana, 2013).

Lalu untuk teori analisis yang digunakan adalah teori Tourism Area Life Cycle (TALC) dari Butler (dalam Pratiwi dkk, 2013). Teori ini digunakan untuk mengetahui eksistensi dari Banjar Samu khususnya mengenai tingkatan siklus hidup area wisata yang sedang dialami oleh Banjar Samu berdasarkan perkembangan yang terjadi pada lokasi tersebut.

\section{METODE PENELITIAN}

Penelitian ini berjenis data kualitatif yang menganalisis data dengan jalan menggambarkan data-data yang diperoleh dalam bentuk penjelasan atau penguraian secara terperinci dan juga menggunakan data kuantitatif (Kusmayadi dan Sugiarto, 2000). Sedangkan untuk sumber data menggunakan data primer dan sekunder (Bungin, 2013). Observasi, wawancara dan dokumentasi merupakan teknik pengumpulan data. Jenis observasi yang digunakan adalah observasi langsung, dari teknik ini data yang diperoleh berupa lokasi penelitian serta potensi wisata yang terdapat di Banjar Samu. Wawancara yang digunakan ialah wawancara mendalam, teknik ini digunakan untuk memperoleh informasi secara jelas dan mendalam terkait dengan potensi wisata yang dimiliki oleh Banjar Samu. Selanjutnya dokumentasi digunakan untuk mengambil foto atau gambar mengenai potensi wisata yang ada di Banjar Samu. Untuk teknik penentuan informan menggunakan purposive sampling dari Kusmayadi dan Sugiarto (2000). Deskriptif kualitatif dan analisis SWOT (Rangkuti, 2015) adalah teknik analisis data yang digunakan dalam penelitian ini.

\section{HASIL DAN PEMBAHASAN}

Banjar Samu merupakan satu dari lima banjar yang ada di Desa Singapadu Kaler, Kecamatan Sukawati, Kabupaten Gianyar. Lokasi Banjar Samu cukup strategis karena berjarak 35 km dari Bandara Internasional I Gusti Ngurah Rai dan $24 \mathrm{Km}$ dari Kantor Gubernur, Denpasar dengan waktu tempuh \pm 1 jam. Pada tanggal 27 September 2015, Bupati Gianyar Anak Agung Gde Agung Baratha Secara resmi telah menetapkan Banjar Samu sebagai desa wisata. Penetapan ini berdasarkan atas daya dukung potensi wisata yang dibisa dimanfaatkan menjadi daya tarik wisata.

Dilihat dari segi geografis, Banjar samu memiliki luas lahan pertanian sebesar 40,16 Ha yang terbagi menjadi dua wilayah subak. Sebagai daerah agraris, padi merupakan tanaman mayoritas utama yang dihasilkan selain tanaman kebun seperti semangka, cabai, jagung, kanggung dan bunga pacah yang umumnya digunakan masyarakat Bali ketika terdapat 
upacara keagamaan. Adapun batas-batas wilayah dari Banjar Samu yakni Desa Singakerta berada di sebelah utara, Desa Lod Tunduh di sebelah selatan, Banjar Belang di sebelah timur dan Mekar Buana di sebelah barat.

Dari monografi Desa Singapadu Kaler di tahun 2015 menunjukkan bahwa jumlah KK (Kepala Keluarga) di Banjar Samu mencapai 403 KK dengan jumlah penduduk mencapai 1.991 jiwa. Saat ini, Sebanyak 976 jiwa berjenis kelamin laki-laki dan sisanya 1.015 jiwa berjenis kelamin perempuan. Sebagian besar tingkat pendidikan masyarakat Banjar Samu didominasi oleh tamatan SMA sebanyak 453 orang atau sebesar 32,87\%. Sedangkan dari mata pencaharian masyarakat didominasi oleh petani/ buruh sebanyak 639 orang dengan presentase sebesar 38,89\% berdasarkan data dari monografi Desa Singapadu Kaler pada tahun 2009.

Hasil penelitian ini menunjukkan bahwa adapun potensi wisata yang dimiliki Banjar Samu dapat dibagi menjadi dua meliputi potensi alam dan budaya. Potensi alam Banjar Samu terdiri dari 1) panorama persawahan. Meski kondisi persawahan bersifat datar, areal persawahan tersebut dilengkapi dengan latar alami berupa adanya sunset yang bisa disaksikan disebelah selatan desa, sehingga persawahan ini tidak kalah menarik dengan persawahan lainnya. 2) Sumber mata air. Banjar Samu mempunyai dua sumber mata air, dimana satu sumber air tersebut dimanfaatkan sebagai air minum dan juga tempat mandi oleh masyarakat. Sedangkan, sumber air lainnya dimanfaatkan sebagai air suci ketika terdapat kegiatan upacara keagamaan di pura ataupun persembahyangan sehari-hari.

Mengenai potensi budaya yang dimiliki Banjar Samu meliputi: 1) kegiatan keseharian masyarakat, sebagian besar aktivitas keseharian masyarakat lokal didominasi oleh masyarakat yang bermata pencaharian sebagai petani/ buruh, 2) keramahtahaman dan sikap gotong royong masyarakat, 3) pura dan aktivitas keagamaan yang dilakukan masyarakat setiap enam bulan sekali di Pura Penataran, Pura Pelinggih, Pura Subak Samu, Pura Puncak Sari, Pura Puseh dan juga Pura Desa. 4) kesenian, kesenian ialah bagian dari unsur kebudayaan yang bernilai tinggi untuk menunjang pengembangan desa wisata di Banjar Samu. Banjar samu memiliki banyak kesenian satu diantaranya bersifat sakral yakni adanya kesenian barong landung. Adapun beberapa kesenian yang bersifat hiburan yakni arja, gambelan geguntangan dan jogged bumbung, serta terdapat kerajinan masyarakat lokal seperti kerajinan seni ukir kayu dan kerajinan perak, 5) adanya aktivitas yoga-meditasi yang berlokasi di Griya Tauman, 6) sekaa atau kelompok seperti (sekaa geguntangan, gong, angklung, joged, santi, subak, kelompok budidaya ikan lele serta jamur tiram).

Selain wisata alam, Keberadaan sekaa mampu menjadi salah satu atraksi wisata budaya yang dapat disaksikan oleh wisatawan. Demi mendukung kelestarian seni-budaya di Banjar Samu maka ketersedian tempat berupa sanggar seni sangat dibutuhkan. Saat ini, Banjar Samu hanya mempunyai dua sanggar seni yakni Sanggar Putu yang berada di Tempekan Tauman Sisi dan Sanggar I Wayan Darmaja yang berada di Tempekan Kaja Kauh.

Ketika penelitian ini dilakukan pada tahun 2016, sesuai dengan ciri-ciri yang terdapat pada tahapan teori tourism area life cycle Banjar Samu berapa pada tahap involvement atau keterlibatan. Agar pengembangan yang dilakukan dapat berjalan dengan baik, setidaknya tahapan yang mesti dicapai yakni pada tahap development atau pembangunan. Sesuai pada ciri tahapan involvement, partisipasi antara pemerintah, masyarakat dan pihak swasta sangat dibutuhkan demi memaksimalkan pengembangan suatu daya tarik wisata agar penyediaan fasilitas wisata serta pelayanan yang diberikan kepada wisatawan dapat diterapkan.

Sejauh ini, pastisipasi yang telah dilakukan masyarakat sudah baik, hal tersebut dapat dilihat dari kuatnya semangat masyarakat yang ikut bekerjasama melakukan aktivitas gotong royong setiap hari minggu pagi mulai dari jam enam sampai jam tujuh dan ikut dalam pelatihan kepariwisataan diberikan oleh perguruan tinggi atas kerjasama yang dilakukan dengan pemerintah (Dinas Pariwisata Kabupaten Gianyar) berupa pelatihan pramusaji dan tata boga. Untuk memperkenalkan Banjar Samu kepada wisatawan, promosi mengenai desa wisata perlu dilakukan demi menarik minat kunjungan wisatawan. Pencapaian tahap development menjadi penting dan sangat diperlukan seperti membentuk sistem pengelolaan, meningkatkan fasilitas wisata serta membuat atraksi wisata. 
Demi mewujudkan pengembangan Banjar Samu sebagai desa wisata yang pertama kali harus diperhatikan ialah menetapkan strategi yang sesuai agar pengembangan yang dilakukan bisa berjalan dengan baik dan sesuai harapan. Jadi strategi merupakan sebuah kunci untuk memperoleh keunggulan produk yang menarik dan memiliki daya saing yang optimal dari sumber sumber daya yang ada. Berikut ini merupakan analisis matriks SWOT yang digunakan untuk mengembangkan Banjar Samu sebagai desa wisata

Tabel 4.1

Analisis Matriks SWOT Strategi Pengembangan Banjar Samu Sebagai Desa Wisata

\begin{tabular}{|c|c|c|}
\hline \multirow[b]{2}{*}{ Eksternal } & Kekuatan (Strengths) & Kelemahan (Weaknesses) \\
\hline & $\begin{array}{l}\text { 1. Suasana pedesaan asri, } \\
\text { kesenian tradisional. } \\
\text { 2. Motivasi masyarakat tinggi. }\end{array}$ & $\begin{array}{l}\text { 1. fasilitas wisata, promosi } \\
\text { dan anggaran kurang. } \\
\text { 2. Sumber daya masyarakat } \\
\text { minim dan tidak ada sistem } \\
\text { pengelolaan. }\end{array}$ \\
\hline Peluang (Opportunities) & Strategi S0 & Strategi W0 \\
\hline $\begin{array}{l}\text { 1. Tren desa wisata yang } \\
\text { sedang berkembang. } \\
\text { 2. Dukungan pihak luar } \\
\text { (Dinas Pariwisata } \\
\text { Kabupaten Gianyar dan } \\
\text { perguruan tinggi) }\end{array}$ & $\begin{array}{l}\text { 1. Peningkatkan kualitas } \\
\text { potensi wisata. } \\
\text { 2. Menetapkan kegiatan } \\
\text { wisata yang sesuai. }\end{array}$ & $\begin{array}{l}\text { 1. Peningkatkan kerjasama } \\
\text { antara desa dan } \\
\text { pemerintah. } \\
\text { 2. Melakukan kerjasama } \\
\text { dengan perguruan tinggi } \\
\text { 3. Membuat promosi. }\end{array}$ \\
\hline Ancaman (Threats) & Strategi ST & Strategi WT \\
\hline $\begin{array}{l}\text { 1. Persaingan atraksi } \\
\text { wisata sejenis. } \\
\text { 2. Tingkat kriminalitas } \\
\text { tinggi. }\end{array}$ & $\begin{array}{l}\text { 1. Meningkatkan keamanan } \\
\text { desa. }\end{array}$ & $\begin{array}{l}\text { 1. Mengadakan penyuluhan. } \\
\text { 2. Membuat sistem } \\
\text { pengelolaan desa wisata. }\end{array}$ \\
\hline
\end{tabular}

Berdasarkan hasil analisis matriks SWOT yang disajikan dalam tabel 4.1 menunjukkan bahwa strategi yang memadukan kekuatan dengan peluang menghasilkan strategi SO meliputi: 1) peningkatkan kualitas potensi wisata. 2) menetapkan kegiatan wisata yang sesuai. Perpaduan antara kelemahan dengan peluang menghasilkan strategi WO meliputi: 1) Peningkatkan kerjasama antara desa dan pemerintah. 2) Melakukan kerjasama dengan perguruan tinggi. 3) Membuat promosi. Perpaduan antara kekuatan dengan ancaman menghasilakn strategi ST meliputi: 1) Meningkatkan keamanan desa. Perpaduan antara kelemahan dengan ancaman menghasilkan strategi WT meliputi: 1) Mengadakan penyuluhan. 2) Membuat sistem pengelolaan desa wisata.

\section{SIMPULAN DAN SARAN}

Dari hasil pemaparan di atas menunjukkan bahwa potensi wisata yang terdapat di Banjar Samu terdiri dari potensi alam meliputi: 1) hamparan persawahan, 2) terdapatnya dua sumber mata air. Sedangkan, dari potensi budaya meliputi: 1) kegiatan keseharian masyarakat, 2) sikap gotong royong dan keramahtamahan masyarakat, 3) pura meliputi arsitektur bangunan beserta kegiatan keagamaan, 4) kesenian yang terdiri dari barong landung sebagai kesenian sakral serta arja, gambelan geguntangan dan joged bumbung sebagai kesenian hiburan dan juga terdapat kerajinan seni ukir kayu yang dibuat oleh masyarakat lokal, 5) adanya kegiatan yogameditasi, 6) sekaa atau kelompok adat (sekaa geguntangan, gong, angklung, joged, santi, subak, kelompok budidaya ikan lele serta jamur tiram).

Berdasarkan hasil yang telah didapat melalui analisis matriks SWOT terdiri dari strategi yang memadukan kekuatan dengan peluang menghasilkan SO: 1) peningkatkan kualitas potensi wisata. 2) menetapkan kegiatan wisata yang sesuai. Perpaduan antara kelemahan dengan peluang menghasilkan strategi WO meliputi: 1) Peningkatkan kerjasama antara desa dan pemerintah, 2) Melakukan kerjasama dengan perguruan tinggi, 3) Membuat promosi. Perpaduan antara kekuatan dengan ancaman menghasilakn strategi ST meliputi: 1) Meningkatkan keamanan desa. Perpaduan antara kelemahan dengan ancaman menghasilkan strategi WT meliputi: 1) Mengadakan penyuluhan, 2) Membuat sistem pengelolaan desa wisata.

Beberapa saran yang bisa dijadikan masukkan untuk mendukung pengembangan Banjar Samu, yaitu: 1) mengadakan penyuluhan dan pelatihan dibidang pariwisata guna meningkatkan kualitas sumber daya masyarakat, 2) melakukan pemasaran melalui website dan memanfaatkan media sosial seperti facebook, twitter dan instagram, 3) memperbaikan dan menyediaan fasilitas wisata yang dibutuhkan seperti papan petunjuk jalan, toilet, art shop, rumah makan dan juga home stay, 4) segera membuat sistem pengelolaan desa wisata yang diawasi oleh kepala dengan melibatkan organisasi subak, desa adat termasuk masyarakat lokal.

Daftar Pustaka:

Bungin, M. Burhan. 2013. Metode Penelitian Sosial \& Ekonomi (Format-Format Kuantitatif dan Kualitatif Untuk Studi Sosiologi, Kebijakan Publik, Komunikasi, Manajemen, dan Pemasaran). Jakarta: Kencana.

Kusmayadi dan Endar Sudiarto. 2000. Metode Penelitian Dalam Bidang Kepariwisataan. Jakarta: PT. Gramedia Pustaka. 
Pendit, Nyoman S. 1999. Ilmu Pariwisata Sebuah Pengantar Perdana. Jakarta : Pradya Paramita.

Pratiwi, Wahyuni dkk. 2013. Ada Apa dengan Pondok Wisata? Seluk Beluk Keberadaan Pondok Wisata di Ubud. Penelitian Lapangan II. Fakultas Pariwisata: Universitas Udayana.

Putra, Agus Muriawan. 2006. Konsep Desa Wisata. (Jurnal Manajemen Pariwisata, Juni 2006, Volume 5, Nomor 1). Dosen D4 Pariwisata Universitas Udayana.

Rangkuti, Freddy. 2015. Analisis SWOT Teknik Membedah Kasus Bisnis. Jakarta: PT. Gramedia Pustaka Utama.

Sudana, I Putu. 2013. Strategi Pengembangan Desa Wisata Ekologis di Desa Belimbing, Kecamatan Pupuan Kabupaten Tabanan. Jurnal Analisis Pariwisata Kajian Kritis Kepariwisataan. Vol. 13, No. 1, 2013 , Hal 11.

Surina, Ni Wayan dan Ida Bagus Nyoman Wartha. 2014. Pura Puseh, Pura Desa Batuan Dalam Perkembangan Kepariwisataan Bali Di Desa Batuan, Kecamatan Sukawati, Kabuapten Gianyar (Kajian Paiwisata Budaya). Jurnal Santiaji Pendidikan Vol. 4, No. 1.

Yoeti, Oka A. 2008. Perencanaan dan Pengembangan Pariwisata. Jakarta: PT. Pradnya Paramita.

http://lifestyle.okezone.com/read/2016/01/03/406/1279 701/bali-terbaik-di-asia-kedua-di-dunia diakses 12 Pebruari 2016.

http://www.disparda.baliprov.go.id/id/Bali-Terpilihsebagai-Pulau-Tujuan-Wisata-Terbaik-di-Asia-Pasifik diakses 14 Pebruari 2016. 